\title{
Can the Prior Cathodic Polarisation Treatment Remove the Air-Formed Surface Film and Is It Necessary for the Potentiodynamic Polarisation Test?
}

\author{
Zheng-Rong Ye ${ }^{1} \cdot$ Zhi-Chao Qiu $^{1} \cdot$ Zheng-Bin Wang $^{2} \cdot$ Yu-Gui Zheng ${ }^{2} \cdot$ Ran Yi $^{1} \cdot$ Xiang Zhou $^{1}$
}

Received: 17 November 2019 / Revised: 6 January 2020 / Published online: 28 March 2020

(c) The Chinese Society for Metals (CSM) and Springer-Verlag GmbH Germany, part of Springer Nature 2020

\begin{abstract}
This paper clarifies two issues related to the prior cathodic polarisation treatment (PCPT) for the potentiodynamic polarisation test: whether PCPT can (1) remove the air-formed surface film and (2) affect the polarisation test results. X-ray photoelectron spectroscopy analyses of fluoride ion-labelled samples show that PCPT cannot remove the surface film completely due to the low reaction rate. Potentiodynamic polarisation tests demonstrate that PCPT with proper operating parameters, -1.0 $V_{\mathrm{SCE}}$ for $5 \mathrm{~min}$ with subsequent open circuit potential (OCP) stabilisation in this study, is necessary because it can improve the test reproducibility without affecting the corrosion parameters by unifying the initial surface state. However, PCPT with lower potentials, longer time or no OCP stabilisation has significant effects on the electrochemical corrosion parameters due to the hydrogen absorption under the conditions of this study.
\end{abstract}

Keywords Stainless steel $\cdot$ Prior cathodic polarisation treatment $\cdot$ Surface film $\cdot$ Potentiodynamic polarisation

\section{Introduction}

Among the electrochemical tests, the potentiodynamic polarisation test is a quite common method to evaluate the corrosion resistance by obtaining the electrochemical corrosion parameters that mainly include the corrosion potential $\left(E_{\text {corr }}\right)$, corrosion current density $\left(I_{\text {corr }}\right)$, pitting potential $\left(E_{\text {pit }}\right)$ and passive current density $\left(I_{\text {pass }}\right)$, owing to its relatively high accuracy and reliability $[1,2]$. The result of potentiodynamic polarisation test is usually affected by the prior surface treatments, such as surface polishing, prior polarisation and pickling $[3,4]$. Therefore, proper prior surface treatment is important for the potentiodynamic polarisation test. The authors have made statistics that nearly $30 \%(18 / 64)$ papers, among those published in corrosionrelated journals in recent 5 years, employed prior cathodic

Zheng-Bin Wang

zbwang12s@imr.ac.cn

Research Institute of Petroleum Exploration and Development, PetroChina, Beijing 100083, China

2 CAS Key Laboratory of Nuclear Materials and Safety Assessment, Institute of Metal Research, Chinese Academy of Sciences, Shenyang 110016, China polarisation treatment (PCPT) before measuring the potentiodynamic polarisation curves of stainless steels, by using "potentiodynamic polarisation" and "stainless steel" as the searching keywords in the Web of Science. It suggests that prior cathodic polarisation treatment (PCPT) is frequently used for the potentiodynamic polarisation tests of stainless steels.

Many researchers claimed that the aim of employing PCPT was to remove the surface oxide film formed unavoidably when exposed to air during the sample preparation [5-12]. The possible removing mechanism is cathodic reduction at low applied potentials based on the Pourbaix diagrams $[13,14]$. This mechanism prevails for pure ion since Bardwell et al. [15] have reported the complete cathodic reduction of Fe oxide film. However, the surface film of stainless steel consists of not only $\mathrm{Fe}$ oxides but also $\mathrm{Cr}$, Mo and Ni oxides [16]. Schmuki et al. [17] found that the $\mathrm{Cr}_{2} \mathrm{O}_{3} / \mathrm{Fe}_{2} \mathrm{O}_{3}$ oxide film was stable against cathodic reduction when the $\mathrm{Cr}_{2} \mathrm{O}_{3}$ concentration was high. Similarly, Ferreira et al. [18] discovered that the $\mathrm{Cr}$ oxide surface layer on 304 stainless steel was still present after cathodic reduction. It seemingly means that the Cr oxide-containing surface film on stainless steel cannot be cathodically reduced completely. Summarily, to our best knowledge, no evidence can be found to support the complete cathodic reduction of surface film 
formed on stainless steels. Accordingly, the common idea that PCPT is used to remove the air-formed surface film is doubtful. If PCPT cannot completely remove the air-formed film, is it still necessary to employ PCPT? This question depends on the effects of PCPT on the electrochemical corrosion parameters obtained from the potentiodynamic polarisation curves. If it can improve the test errors without affecting the absolute values of corrosion parameters [4], PCPT is indeed necessary for the potentiodynamic polarisation test. Otherwise, it is not a suitable pretreatment method. However, seldom investigations focus on the effects of PCPT on the electrochemical corrosion of stainless steels [19]. Therefore, the necessity of PCPT for the potentiodynamic polarisation test still needs further clarification.

Based on the summary above, there are two issues concerned with the PCPT: (1) whether it can completely remove the air-formed surface film on stainless steel and (2) whether it is necessary for the potentiodynamic polarisation test. Addressing such two issues is undoubtedly helpful for understanding the mechanism of PCPT and can provide some guidance for the employment of PCPT as the sample pretreatment before the potentiodynamic polarisation test. This paper aims to fulfil the purposes mentioned above by investigating the effects of PCPT with different operating parameters on the surface film and the electrochemical corrosion behaviour of AISI 316 stainless steel (316 SS) in 3.5 $\mathrm{wt} \% \mathrm{NaCl}$ solution, using the electrochemical methods and surface characterisation.

\section{Experimental}

\subsection{Materials and Surface Preparation}

The stainless steel used in this study was cut from an asreceived 316 SS sheet by the wire-electrode cutting. After being ground and degreased, the sample was sealed in epoxy resin with the exposed area of $1 \mathrm{~cm}^{2}$, which was used as the working electrode. Then, the surface of working electrode was mechanically ground to $1000^{\#}$ with a series of silicon carbide abrasive papers and was subsequently cleaned with ethanol for $5 \mathrm{~min}$ and dried in hot air for $1 \mathrm{~min}$, before the electrochemical measurements.

\subsection{Electrochemical Measurements}

All the electrochemical measurements were performed in the three-electrode cell setup using a Gamry Reference 600 electrochemical workstation. The three electrodes consisted of a sample as the working electrode, a Pt foil with larger surface area as the counter electrode, and a saturated calomel electrode (SCE) as the reference electrode that was connected to the cell via a salt bridge with a Luggin capillary.
Before the potentiodynamic polarisation test, the PCPT was carried out using the potentiostatic polarisation mode. The applied cathodic potential was set as $-1.0 V_{\mathrm{SCE}},-1.2 V_{\mathrm{SCE}}$ and $-1.4 V_{\mathrm{SCE}}$, and the polarisation time was set as $5 \mathrm{~min}$, $10 \mathrm{~min}$ and $30 \mathrm{~min}$, referring to the operating parameters in the literature [5-12] and the Pourbaix diagrams [13, 14]. Subsequently, the potentiodynamic polarisation test was conducted with and without the subsequent open circuit potential (OCP) stabilisation. For the former case, the OCP was firstly monitored for $30 \mathrm{~min}$ after PCPT, and then, the potential scanning was started from $-0.3 \mathrm{~V}$ versus OCP in anodic direction and terminated when the current density reached $1 \mathrm{~mA} / \mathrm{cm}^{2}$. For the case without OCP stabilisation, the potentiodynamic polarisation test was started immediately by sweeping the potential from the applied cathodic potential to the higher potential where the current density reached $1 \mathrm{~mA} / \mathrm{cm}^{2}$. For all the potentiodynamic polarisation tests, the potential scanning rate was set as $1 \mathrm{mV} / \mathrm{s}$. All the electrochemical measurements were conducted in the aerated and unstirred $3.5 \mathrm{wt} \% \mathrm{NaCl}$ solution with the temperature maintained at $25 \pm 1{ }^{\circ} \mathrm{C}$. Each electrochemical test was repeated at least four times to ensure the reproducibility.

\subsection{Surface Characterisation}

In the present study, a pre-formed surface film labelled by fluoride ion $\left(\mathrm{F}^{-}\right)$was specially prepared in order to clarify whether the PCPT can completely remove the surface film on stainless steel. This ion labelling method has been applied to confirm the mechanical rupture of surface film in the erosion-corrosion process in our previous work [20]. In this paper, the ion labelling was performed by immersing the $316 \mathrm{SS}$ sample in the $0.05 \mathrm{M} \mathrm{H}_{2} \mathrm{SO}_{4}+0.005 \mathrm{M} \mathrm{F}^{-}$solution for $24 \mathrm{~h}$, in which the surface film containing $\mathrm{F}^{-}$formed [16]. It has been confirmed that this pre-formed surface film mainly consists of $\mathrm{Fe}, \mathrm{Cr}$, $\mathrm{Ni}$ and Mo oxides, which are also the oxides existing in the film formed in air at room temperature $[16,21]$. Then, the sample with pre-formed ionlabelled film was cathodically polarised at $-1.4 V_{\mathrm{SCE}}$ for $30 \mathrm{~min}$ in $3.5 \mathrm{wt} \% \mathrm{NaCl}$ solution. The $\mathrm{X}$-ray photoelectron spectroscopy (XPS) was used to characterise the changes in the surface film compositions before and after the PCPT, by using an ESCALAB250 X-ray photoelectron spectrometer with a monochromatic $\mathrm{Al} K \alpha(1486.6 \mathrm{eV})$ radiation source. The X-ray gun was operated at $150 \mathrm{~W}(15 \mathrm{kV}, 10 \mathrm{~mA})$ and the photoelectron take-off angle was $90^{\circ}$. During the experiments, the base pressure was maintained at approximately $10^{-8} \mathrm{~Pa}$. High resolution spectra with an analyzed area of $500 \mu \mathrm{m}^{2}$ were recorded with the pass energy of $50.0 \mathrm{eV}$, the energy step of $0.1 \mathrm{eV}$ and the energy resolution of $0.5 \mathrm{eV}$. High resolution surface spectra of $\mathrm{F} 1 s$ and $\mathrm{C} 1 s$ were registered, and the values of binding energies were aligned to carbon peak $\mathrm{C} 1 s$ at $284.6 \mathrm{eV}$. 


\section{Results and Discussion}

\subsection{Possible Reactions Occurring During the Prior Cathodic Polarisation}

Figure 1 shows the current density-time curves of prior cathodic polarisation tests at various applied potentials and polarisation time. Negative (cathodic) current can be identified for all cases. In the cases of $-1.0 V_{\mathrm{SCE}}$ and $-1.2 V_{\mathrm{SCE}}$, the cathodic polarisation current density changes little after $5 \mathrm{~min}$, whilst it increases gradually in the negative direction with prolonging the polarisation time at $-1.4 V_{\mathrm{SCE}}$. The cathodic polarisation current densities at $-1.0 V_{\mathrm{SCE}},-1.2 V_{\mathrm{SCE}}$ and $-1.4 V_{\mathrm{SCE}}$ vary approximately from $-0.04 \mathrm{~mA} / \mathrm{cm}^{2}$ to $-0.2 \mathrm{~mA} / \mathrm{cm}^{2},-0.4 \mathrm{~mA} / \mathrm{cm}^{2}$ to $-0.6 \mathrm{~mA} / \mathrm{cm}^{2}$ and $-5.8 \mathrm{~mA} /$ $\mathrm{cm}^{2}$ to $-7.4 \mathrm{~mA} / \mathrm{cm}^{2}$, respectively, during the polarisation. Bardwell et al. [15] and Schmuki et al. [17] reported that Fe oxides can be cathodically reduced at a current density as low as $-0.01 \mathrm{~mA} / \mathrm{cm}^{2}$. Meanwhile, the investigations made by $\mathrm{Yu}$ et al. implied that the cathodic current density of $-0.1 \mathrm{~mA} /$ $\mathrm{cm}^{2}$ was enough for the hydrogen charging (hydrogen absorption) of ion [22-24], and we also observed the bubbles produced on the sample surface during the prior cathodic polarisation tests, indicating the occurrence of cathodic hydrogen evolution reaction (HER). Additionally, the cathodic oxygen reduction reaction (ORR) can also proceed under the aerated condition of present study. Accordingly, the HER, film reduction reaction and ORR can probably occur during the prior cathodic polarisation. Herein, the possible occurrence of film reduction reaction means that the air-formed film could be supposedly removed by the reduction mechanism, the clarification of which will be performed in the following section.

\subsection{Confirming Whether PCPT Can Remove the Oxide Film}

Figure 2 presents the detailed F $1 s$ XPS spectra of the sample with pre-formed surface film labelled by $\mathrm{F}^{-}$before and after PCPT. Obvious F $1 s$ peaks with identical position can be recognised for both the two cases. Since the amount of $\mathrm{F}^{-}$in the film is quite small according to our previous work [16] and the binding energies of $\mathrm{Cr}, \mathrm{Fe}$ and $\mathrm{Ni}$ fluoride compounds are similar based on the NIST XPS database [25], it is of difficulty to decompose the detailed $\mathrm{F} 1 s$ spectra in Fig. 2. Nonetheless, the F $1 s$ peaks in Fig. 2 can be approximately identified at $685 \pm 1 \mathrm{eV}$, corresponding to the fluoride compounds of $\mathrm{CrF}_{3}, \mathrm{FeF}_{3}$ and $\mathrm{NiF}_{3}$ [25]. These compounds resemble to those contained in the pre-formed film [16]. Keeping in mind that the cathodic polarisation is conducted in fluoride-free solution, it can be concluded that the PCPT does not remove the pre-formed film even if the applied potential is as negative as $-1.4 V_{\mathrm{SCE}}$ and the polarisation time is as relatively long as $30 \mathrm{~min}$. This finding seems to contradict the speculation in Sect. 3.1, as well as the common standpoint held by many other researchers that PCPT can remove the air-formed surface film on stainless steels, which therefore needs explanation.

In the single liquid-phase media, the surface film can be generally removed by the dissolution or cathodic reduction

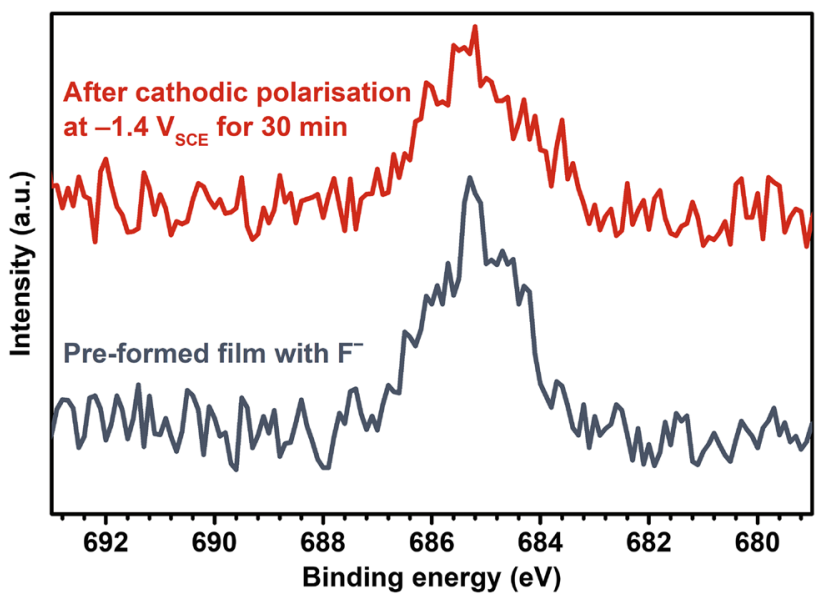

Fig. 2 Detailed F $1 s$ XPS spectra of pre-formed film containing fluoride ion $\left(\mathrm{F}^{-}\right)$before and after PCPT
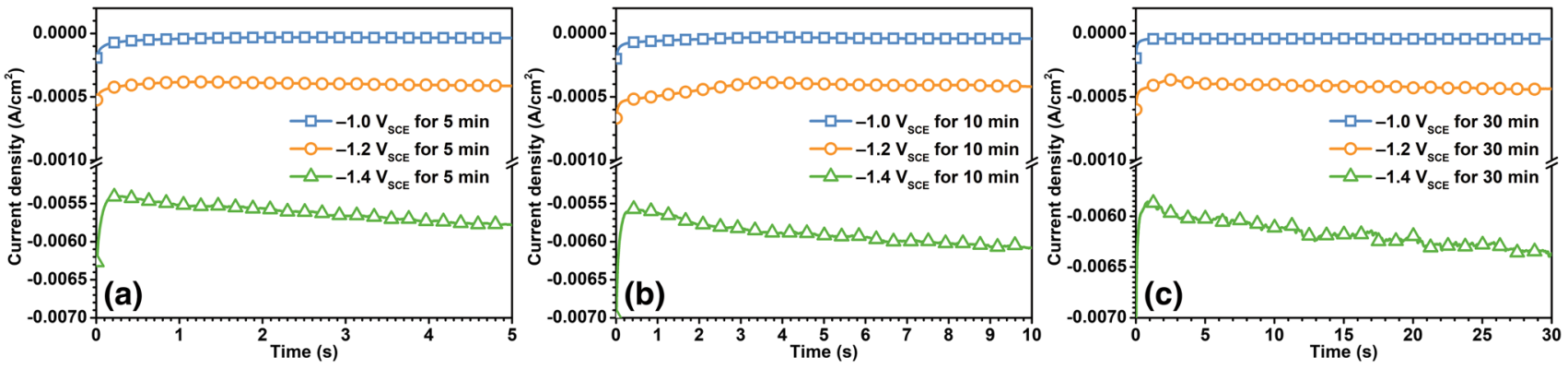

Fig. 1 Current density-time curves of prior cathodic polarisation tests at $-1.0 V_{\mathrm{SCE}},-1.2 V_{\mathrm{SCE}}$ and $-1.4 V_{\mathrm{SCE}}$ for a $5 \mathrm{~min}$, b $10 \mathrm{~min}$, c $30 \mathrm{~min}$ 
mechanism. Considering that the surface film on 316 SS is mainly composed of $\mathrm{Cr}$ oxide and $\mathrm{Cr}$ hydroxide [11, 16], only the $\mathrm{Cr}_{2} \mathrm{O}_{3}$ is herein considered when discussing the removing of surface film. Below are the possible dissolution and cathodic reduction mechanisms of $\mathrm{Cr}_{2} \mathrm{O}_{3}$ during PCPT $[14,16]$.

Dissolution mechanism : $\quad \mathrm{Cr}_{2} \mathrm{O}_{3}+6 \mathrm{H}^{+} \stackrel{\mathrm{Cl}^{-}}{\longrightarrow} 2 \mathrm{Cr}^{3+}+3 \mathrm{H}_{2} \mathrm{O}$ nitrogen-containing type $316 \mathrm{~L}$ stainless steel in $0.5 \mathrm{M} \mathrm{NaCl}$ solution [26]. In addition, the feature of cathodic diffusion can be also observed in Fig. 3b, $\mathrm{d}$ and $\mathrm{f}$ for the cases without OCP stabilisation. Commonly, this diffusion feature is bound to appear at more negative potentials in the aerated solution [27]. In fact, we also swept the polarisation curves to more negative potentials for the cases with OCP stabilisation and observed the similar diffusion feature (now shown). Therefore, the diffusion feature in the cathodic portion is not

Cathodic reduction mechanism: $\mathrm{Cr}_{2} \mathrm{O}_{3}+6 \mathrm{H}^{+}+2 \mathrm{e}^{-} \rightarrow 2 \mathrm{Cr}^{2+}+3 \mathrm{H}_{2} \mathrm{O}$

Reaction (1) is a chemical dissolution reaction catalysed by the chloride ion $\left(\mathrm{Cl}^{-}\right)$, in which the $\mathrm{Cl}^{-}$dissolves the $\mathrm{Cr}$ oxide by replacing the oxygen ions [16]. This dissolution reaction has been confirmed to occur for $316 \mathrm{SS}$ in chloridecontaining solution by our previous work [16]. Reaction (2) is an electrochemical reaction, whose equilibrium potential $\left(E_{\mathrm{e}}\right)$ is about $-0.9 V_{\mathrm{SCE}}$ in near-neutral solution based on the Pourbaix diagram for chromium at $25^{\circ} \mathrm{C}$ [14]. The feature of $E_{\mathrm{e}}>-1.0 V_{\mathrm{SCE}}$ suggests that reaction (2) should also probably occur, which is in agreement with the discussion in Sect. 3.1. The possible occurrence of reaction (1) and reaction (2) in thermodynamics indicates that the failure of PCPT to remove the surface film can be ascribed to the slow reaction rate in kinetics. Apart from reaction (1) and reaction (2), HER, a $\mathrm{H}^{+}$consuming reaction, must occur during PCPT, as confirmed in Fig. 1. It means that HER competes with reaction (1) and reaction (2) that also consume $\mathrm{H}^{+}$. In contrast to the other two reactions, no solid phase is involved in HER, making it more prone to occur on the surface. In this situation, HER hinders reaction (1) and reaction (2), leading to slow reaction rate consequently. As a result, the film cannot be completely removed by reaction (1) and reaction (2) in the limited time interval of PCPT.

\subsection{Effects of PCPT on Electrochemical Corrosion Parameters}

Figure 3 presents the potentiodynamic polarisation curves after PCPT with and without subsequent open circuit potential (OCP) stabilisation. Two obvious phenomena can be identified: (1) the pitting potential $\left(E_{\text {pit }}\right)$ decreases while the change in corrosion current density $\left(I_{\text {corr }}\right)$ is not as recognisable as $E_{\text {pit }}$ after PCPT with OCP stabilisation (Fig. 3a, c, e), and (2) significant difference between the polarisation curves with and without PCPT is noticed when no OCP stabilisation is applied, which is mainly reflected in the decreased $E_{\text {pit }}$, decreased corrosion potential $\left(E_{\text {corr }}\right)$, extended passive potential region and suppressed cathodic curve (Fig. 3b, d, f). Similar phenomenon to the latter one has been found by Ningshen et al. for the hydrogen pre-charged $\left(-50 \mathrm{~mA} / \mathrm{cm}^{2}\right)$ the difference between the curves with and without OCP stabilisation.

In order to assess the effects of PCPT on the potentiodynamic polarisation curves more quantitatively and clearly, the electrochemical corrosion parameters of $E_{\text {corr }}, I_{\text {corr }}, I_{\text {pass }}$ and $E_{\mathrm{pit}}$ are obtained from the polarisation curves shown in Fig. 3. $E_{\text {corr }}$ was directly determined as the potential with the lowest current density in the polarisation curve [16]. $I_{\text {corr }}$ for the cases with OCP stabilisation was obtained by cathodic Tafel fitting because typical Tafel feature is identified only for the cathodic portion (Fig. 3a, c, f), while $I_{\text {corr }}$ for the cases without OCP stabilisation was regarded to be roughly equal to $I_{\text {pass }}$ due to the typical spontaneous passive behaviour (Fig. 3b, d, e) [28]. $I_{\text {pass }}$ was determined as the current density at $0 V_{\mathrm{SCE}}$ and $-0.2 V_{\mathrm{SCE}}$ for the cases with and without OCP stabilisation, respectively, considering the different passive potential regions [16, 28]. $E_{\mathrm{pit}}$ was regarded as the potential from which the anodic current density starts to increase sharply and continuously $[10,12,29,30]$. The determined $E_{\text {corr }}, I_{\text {corr }}, I_{\text {pass }}$ and $E_{\text {pit }}$ values are shown in Fig. 4a-d, respectively. In the cases with OCP stabilisation, PCPT has few effects on $E_{\text {corr }}$ and $I_{\text {corr }}$ except for the case of $-1.4 V_{\mathrm{SCE}}$ for $30 \mathrm{~min}$ (Fig. 4a, b), while $I_{\text {pass }}$ increases and $E_{\mathrm{pit}}$ decreases with lowering the cathodic potential and prolonging the polarisation time (Fig. $4 \mathrm{c}, \mathrm{d})$. In contrast, when no OCP stabilisation is applied after PCPT, $E_{\text {corr }}$ and $E_{\text {pit }}$ decrease while $I_{\text {corr }}$ and $I_{\text {pass }}$ increase more pronouncedly, deviating tremendously from the corresponding values of the control group. It demonstrates that improper PCPT, with lower applied potential, longer polarisation time and no subsequent OCP stabilisation, has great effects on the electrochemical corrosion parameters.

The phenomena of decreased $E_{\text {corr }}$ and $E_{\text {pit }}$, as well as increased $I_{\text {corr }}$ and $I_{\text {pass }}$, are similar to those induced by the hydrogen charging [3, 22, 26, 31-34]. This similarity implies that the effects of PCPT are attributed to the absorbed hydrogen. It has been clarified that the absorbed hydrogen can deteriorate the film protectiveness by decreasing the thickness, increasing the carrier density or reducing the cationic faction of $\mathrm{Cr}$ in the passive film, which accelerates the anodic 

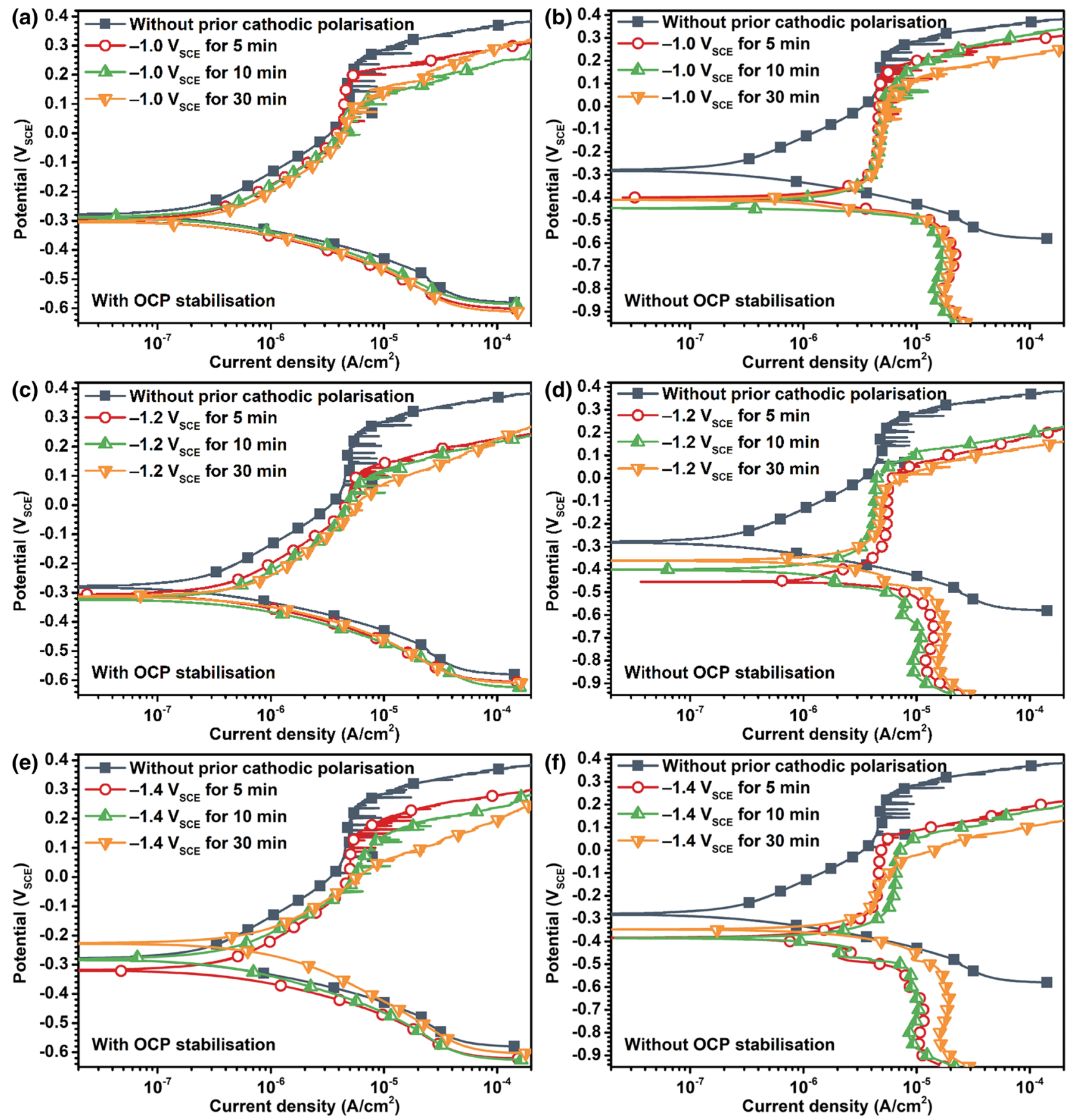

Fig. 3 Potentiodynamic polarisation curves after PCPT at $\mathbf{a}, \mathbf{b}-1.0 V_{\mathrm{SCE}}, \mathbf{c}, \mathbf{d}-1.2 V_{\mathrm{SCE}}$ and $\mathbf{e}, \mathbf{f}-1.4 V_{\mathrm{SCE}}$ with a, c, e and without b, d, f OCP stabilisation. The potential scanning rate is $1 \mathrm{mV} / \mathrm{s}$

dissolution (increased $I_{\text {corr }}$ and $I_{\text {pass }}$ ) and promotes the pitting susceptibility (decreased $E_{\text {pit }}$ ) [8, 22, 31-34]. Moreover, it has been confirmed in Fig. 2 that a film always exists on the surface during PCPT. Consequently, the absorbed hydrogen can interact with this surface film by combining with oxygen ions $\left(\mathrm{O}^{2-}\right)$ to form hydrogen-containing species, such as hydroxide $\left(\mathrm{OH}^{-}\right)$[35]. The formation of $\mathrm{OH}^{-}$can inhibit the cathodic HER. The acceleration of anodic reactions and the inhibition of cathodic reactions finally lead to the decrease of $E_{\text {corr }}$ based on the mixed potential theory [13].

Apparently, the aforementioned effects of PCPT on the electrochemical corrosion parameters can be aggravated with increasing the amount of absorbed hydrogen. PCPT at more negative potentials with longer time results in more 

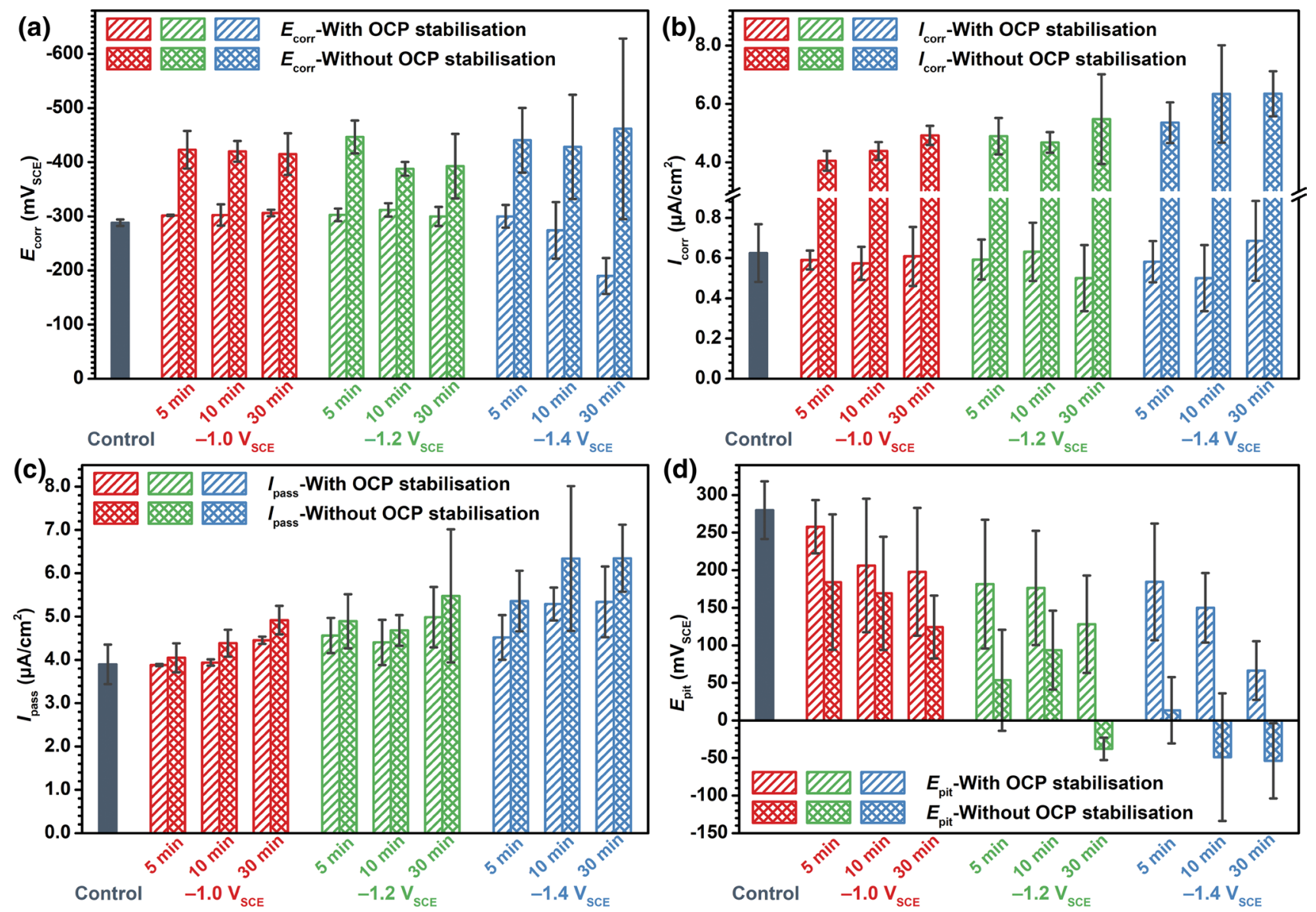

Fig. $4 E_{\text {corr }}, I_{\text {corr }}, I_{\text {pass }}$ and $E_{\text {pit }}$ values obtained from the potentiodynamic polarisation curves of Fig. 3 . The control group is the case without PCPT. The potential scanning rate is $1 \mathrm{mV} / \mathrm{s}$

absorbed hydrogen due to the enhanced HER. Meanwhile, there are commonly two types of hydrogen absorbed in the metal: irreversible and reversible trapped hydrogen [36]. During the process of OCP stabilisation, desorption of the reversible trapped hydrogen occurs and the irreversible trapped hydrogen can be removed concurrently by the dissolution of surface film. As a result, the amount of absorbed hydrogen under the condition without OCP stabilisation is much more than that under the condition with OCP stabilisation. The higher amount of absorbed hydrogen can explain why the electrochemical corrosion parameters are affected so pronouncedly at more negative potentials with longer time, as well as under the condition without OCP stabilisation. It can be reasonably predicted that the effects of PCPT on the electrochemical corrosion parameters are eliminated as long as the amount of absorbed hydrogen is reduced to the ignorable level, which needs less negative polarisation potential, shorter polarisation time and subsequent OCP stabilisation. In this study, $-1.0 V_{\mathrm{SCE}}$ for $5 \mathrm{~min}$ with $30 \mathrm{~min}$ OCP stabilisation is just this case based on Fig. 4.
Furthermore, it is worthy of noting that all the electrochemical corrosion parameters under the PCPT condition of $-1.0 V_{\mathrm{SCE}}$ for $5 \mathrm{~min}$ with OCP stabilisation are not only closest to those of control group, but also exhibit the smallest errors, even smaller than those of the control group. The errors are relatively larger under the other conditions. Schweinsberg and Flitt [4] also reported that the pretreatment with abrasion/polishing followed by anodic/ cathodic polarisation improved the reproducibility of electrochemical corrosion parameters, including $I_{\text {corr }}, E_{\text {corr }}$ and Tafel slopes, for the pure ion in $0.5 \mathrm{M} \mathrm{H}_{2} \mathrm{SO}_{4}$. They believed that it resulted from the effects of pretreatment on the working electrode catalytic activity, which we prefer to call as the surface state [4]. Referring to their explanation, we herein tend to attribute the effects of PCPT on the reproducibility of corrosion parameters to the combined action of surface state change and hydrogen absorption. In general, the initial surface potential, corresponding to the surface state, after PCPT is the same for different parallel samples, improving the reproducibility consequently. This 
mechanism is true for all the cases with different PCPT operating parameters. In contrast, the hydrogen produced during PCPT is prone to be absorbed in the local defects on the surface, such as dislocations, grain boundaries and so on, which can lead to more pronounced heterogeneity of surface state and hence more obvious discrepancy among the parallel samples. This discrepancy results in larger test errors and poor reproducibility. Apparently, the final effect of PCPT on the test reproducibility depends on the competition between these two mechanisms. For the case of $-1.0 V_{\mathrm{SCE}}$ for 5 min with OCP stabilisation, the discrepancy of surface state caused by the absorbed hydrogen is not prevailing due to the ignored amount, and the unification of surface state is dominant, leading to the improved reproducibility.

Conclusively, proper PCPT ( $-1.0 V_{\mathrm{SCE}}$ for $5 \mathrm{~min}$ in this paper) with subsequent OCP stabilisation can improve the reproducibility of electrochemical corrosion parameters under the premise without affecting their absolute values, which is therefore necessary for the potentiodynamic polarisation test.

\section{Conclusions}

1. The XPS analyses of the samples with pre-formed film labelled by fluoride ion confirm that PCPT cannot remove the surface film in the relatively short time interval (30 min), resulting from the slow rates of film dissolution and cathodic reduction reactions.

2. PCPT with proper operating parameters is necessary for the potentiodynamic polarisation test because it can improve the test reproducibility without affecting the absolute values of electrochemical corrosion parameters, which is due to the ignorable amount of absorbed hydrogen and the consistent surface states of parallel samples under the proper PCPT conditions. In the present paper for $316 \mathrm{SS}$ in $3.5 \mathrm{wt} \% \mathrm{NaCl}$, such proper operating parameters are $-1.0 V_{\mathrm{SCE}}$ for $5 \mathrm{~min}$ with subsequent 30 min OCP stabilisation.

3. Improper PCPT with more negative applied potentials, longer polarisation time and no subsequent OCP stabilisation has significant effects on the electrochemical corrosion parameters. It is attributed to the hydrogen absorption deteriorating the film protectiveness.

Acknowledgements This work was supported by the National Science and Technology Major Project of China (No. 2016ZX05016-004), the National Natural Science Foundation of China (Nos. 51801218 and 51571200), and the Strategic Priority Research Program of the Chinese Academy of Sciences (No. XDA13040500).

\section{References}

[1] X.L. Zhang, Z.H. Jiang, Z.P. Yao, Y. Song, Z.D. Wu, Corros. Sci. 51, 581 (2009)

[2] Z.B. Wang, H.X. Hu, C.B. Liu, H.N. Chen, Y.G. Zheng, Acta Metall. Sin. (Engl. Lett.) 28, 477 (2015)

[3] D. Wallinder, G. Hultquist, B. Tveten, E. Hornlund, Corros. Sci. 43, 1267 (2001)

[4] D.P. Schweinsberg, H.J. Flitt, Corros. Sci. 47, 1520 (2005)

[5] M. Sun, M. Luo, C. Lu, T.W. Liu, Y.P. Wu, L.Z. Jiang, J. Li, Acta Metall. Sin. (Engl. Lett.) 28, 1089 (2015)

[6] X.W. Lei, Y.R. Feng, J.X. Zhang, A.Q. Fu, C.X. Yin, D.D. Macdonald, Electrochim. Acta 191, 640 (2016)

[7] S.A. Saadi, Y. Yi, P. Cho, C. Jang, P. Beeley, Corros. Sci. 111, 720 (2016)

[8] G.S. Bai, S.P. Lu, D.Z. Li, Y.Y. Li, Corros. Sci. 108, 111 (2016)

[9] D.D. Liang, X.S. Wei, C.T. Chang, J.W. Li, Y. Yang, X.M. Wang, J. Shen, Acta Metall. Sin. (Engl. Lett.) 31, 1098 (2018)

[10] X.Q. Cheng, Y. Wang, X.G. Li, C.F. Dong, J. Mater. Sci. Technol. 34, 2140 (2018)

[11] X.R. Zhang, J.L. Zhao, T. Xi, M.B. Shahzad, C.G. Yang, K. Yang, J. Mater. Sci. Technol. 34, 2149 (2018)

[12] Y.Y. Yang, Y.Y. Liu, M.L. Cheng, N.W. Dai, M. Sun, J. Li, Y.M. Jiang, Acta Metall. Sin. (Engl. Lett.) 32, 98 (2019)

[13] C.N. Cao, Principles of Electrochemistry of Corrosion, 3rd edn. (Chemical Industry Press, Beijing, 2008)

[14] B. Beverskog, I. Puigdomenech, Corros. Sci. 39, 969 (1997)

[15] J.A. Bardwell, B. Macdougall, M.J. Graham, J. Electrochem. Soc. 135, 413 (1988)

[16] Z.B. Wang, H.X. Hu, Y.G. Zheng, Corros. Sci. 130, 203 (2018)

[17] P. Schmuki, S. Virtanen, H.S. Isaacs, M.P. Ryan, A.J. Davenport, H. Bohni, T. Stenberg, J. Electrochem. Soc. 145, 791 (1998)

[18] M.G.S. Ferreira, N.E. Hakiki, G. Goodlet, S. Faty, A.M.P. Simoes, M.D. Belo, Electrochim. Acta 46, 3767 (2001)

[19] F. Arjmand, A. Adriaens, Corros. Rev. 33, 249 (2015)

[20] Z.B. Wang, Y.G. Zheng, J.Z. Yi, Tribol. Int. 133, 67 (2019)

[21] F.P. Fehlner, M.J. Graham, in Corrosion Mechanisms in Theory and Practice, ed. by P. Marcus (CRC Press, Boca Raton, 2002), p. 174

[22] J.G. Yu, J.L. Luo, P.R. Norton, Appl. Surf. Sci. 177, 129 (2001)

[23] J.G. Yu, J.L. Luo, P.R. Norton, Electrochim. Acta 47, 1527 (2002)

[24] J.G. Yu, J.L. Luo, C.S. Zhang, P.R. Norton, J. Electrochem. Soc. 150, B405 (2003)

[25] NIST X-ray Photoelectron Spectroscopy Database. (2012) http:// srdata.nist.gov/xps/. Accessed 02 Nov 2019

[26] S. Ningshen, U.K. Mudali, Electrochim. Acta 54, 6374 (2009)

[27] Z.B. Wang, H.X. Hu, Y.G. Zheng, J. Solid State Electrochem. 22, 2083 (2018)

[28] Z.B. Wang, H.X. Hu, Y.G. Zheng, W. Ke, Y.X. Qiao, Corros. Sci. 103, 50 (2016)

[29] L.L. Li, Z.B. Wang, Y.G. Zheng, Corros. Sci. 158, 108084 (2019)

[30] Z. Wang, Z.Q. Zhou, L. Zhang, J.Y. Hu, Z.R. Zhang, M.X. Lu, Acta Metall. Sin. (Engl. Lett.) 32, 585 (2019)

[31] H. Yashiro, B. Pound, N. Kumagai, K. Tanno, Corros. Sci. 40, 781 (1998)

[32] Q. Yang, J.L. Luo, J. Electrochem. Soc. 148, B29 (2001)

[33] S. Ningshen, U.K. Mudali, G. Amarendra, P. Gopalan, R.K. Dayal, H.S. Khatak, Corros. Sci. 48, 1106 (2006)

[34] J.Z. Yao, C.F. Dong, C. Man, K. Xiao, X.G. Li, Corrosion 72, 42 (2016)

[35] W.J. Lee, S.I. Pyun, Mater. Sci. Eng., A 279, 130 (2000)

[36] Q. Liu, A. Atrens, Corros. Sci. 96, 112 (2015) 